Viso - Cadernos de estética aplicada Revista eletrônica de estética

ISSN 1981-4062

$N^{\circ} 20$, jan-jun/2017

http://www.revistaviso.com.br/
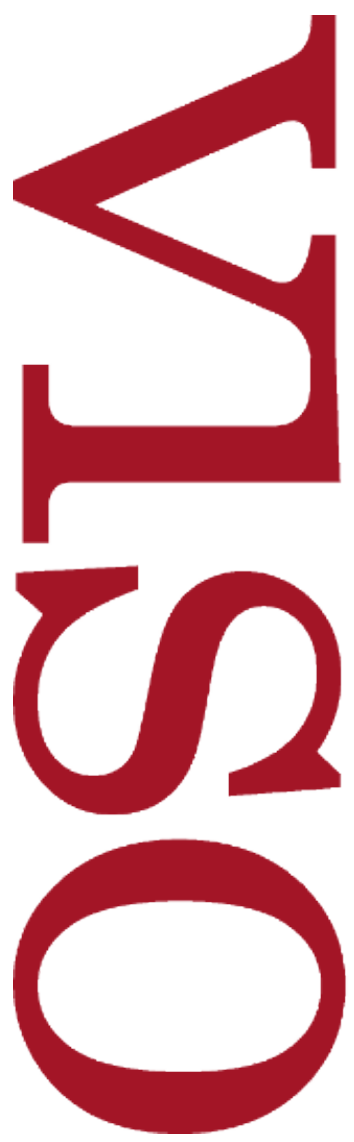

\title{
Interpretar? Deslocar, multiplicar (Nietzsche, Foucault e o sentido em Deleuze) Annita Costa Malufe
}




\section{RESUMO}

Interpretar? Deslocar, multiplicar (Nietzsche, Foucault e o sentido em Deleuze)

O presente artigo discorre acerca das mudanças no conceito de sentido efetuadas por alguns pensamentos filosóficos que se deram na esteira da revolução operada por Friedrich Nietzsche; enfocaremos aqui sobretudo as filosofias de Michel Foucault e Gilles Deleuze, a partir da ideia, proposta por Foucault, de uma "hermenêutica moderna". O objetivo é destacar a problematização do ato de interpretar, tendo no horizonte os deslocamentos que essas novas posturas diante do sentido acarretam para a leitura crítica do texto literário no contemporâneo.

Palavras-chave: sentido - Michel Foucault - Gilles Deleuze - literatura - modernidade

\section{ABSTRACT}

To interpret? Displace, multiplicate (Nietzsche, Foucault and Deleuze's concept of meaning)

This paper discusses the changes in the concept of meaning proposed by some philosophical thoughts that were inspired by from Friedrich Nietzsche revolution. As to do so, we focus here in Michel Foucault and Gilles Deleuze's philosophy, from the Foucault's idea of a "Modern hermeneutic". Our objective is to problematize the interpretation act, intending to highlight the displacements that those new postures can bring for the contemporary literary criticism.

Keywords: meaning - Michel Foucault - Gilles Deleuze - literature - modernity 


\section{MALUFE, A. C. "Interpretar? Deslocar, multiplicar (Nietzsche, Foucault e o sentido em Deleuze)". In: Viso: Cadernos de estética aplicada, v. XI, n. 20 (jan- jun/2017), pp. 69-82.}

DOI: $10.22409 / 1981-4062 / v 20 i / 219$

Aprovado: 10.02.2017. Publicado: 29.06.2017.

(C) 2017 Annita Costa Malufe. Esse documento é distribuído nos termos da licença Creative Commons Atribuição-NãoComercial 4.0 Internacional (CC-BY-NC), que permite, exceto para fins comerciais, copiar e redistribuir o material em qualquer formato ou meio, bem como remixá-lo, transformá-lo ou criar a partir dele, desde que seja dado o devido crédito e indicada a licença sob a qual ele foi originalmente publicado.

Licença: http://creativecommons.org/licenses/by-nc/4.0/deed.pt_BR

Accepted: 10.02.2017. Published: 29.06.2017.

(C) 20172017 Annita Costa Malufe. This document is distributed under the terms of a Creative Commons Attribution-NonCommercial 4.0 International license (CC-BY-NC) which allows, except for commercial purposes, to copy and redistribute the material in any medium or format and to remix, transform, and build upon the material, provided the original work is properly cited and states its license.

License: http://creativecommons.org/licenses/by-nc/4.0/ 
As palavras podem ser perigosas, mentirosas ou simplesmente de difícil compreensão. $O$ fato é que a linguagem verbal sempre fez nascer nos homens dois tipos de suspeita: 1) de que ela não diz exatamente (ou somente) o que ela diz, de que há portanto algo por detrás do que é dito; 2) de que não é apenas ela que fala, mas que há outras coisas no mundo que falam e que não são linguagem, ou seja, de que haveria uma linguagem se articulando de modos não-verbais. São suspeitas que já estariam nos gregos e que falam desta desconfiança do homem com a linguagem e portanto de sua necessidade de criar técnicas de interpretação; é o que nos diz Michel Foucault:

Creio que cada cultura, quero dizer, cada forma cultural na civilização ocidental, teve seu sistema de interpretação, suas técnicas, seus métodos, suas maneiras próprias de supor que a linguagem quer dizer outra coisa do que ela diz, e de supor que há linguagem para além da própria linguagem. ${ }^{1}$

Daí toda uma tradição interpretativa no Ocidente, iniciada nas leituras dos textos míticos, bíblicos e jurídicos, apoiada na necessidade de compreender a relação e a distância entre palavras e coisas, bem como entre o dito e o dizer. Nossos estudos literários são herdeiros dessa tradição e, nas suas mais diversas teorias e posicionamentos teóricos, muitas vezes acabam, mesmo hoje, inspirados por alguns pressupostos da hermenêutica clássica e romântica - a persistência na crença em algum tipo de verdade, ainda que tida como parcial, a importância da intenção do autor, o peso maior dado sempre a um dos lados - ou o escritor ou o leitor será mais responsável pelo sentido verdadeiro (conforme a teoria em questão pese mais na origem ou na destinação do texto), por exemplo.

Junto disso, assiste-se, talvez desde fins do século XIX, a tentativas de leitura da arte que escapem de certas determinações da razão. E que acolham um tipo de sentido mais fugidio, flutuante, para dar conta de algumas propostas da arte que começavam a surgir. Antes mesmo das vanguardas históricas, as leituras da literatura precisavam correr atrás de toda uma poesia, por exemplo, que afirmava uma linguagem distante do entendimento, frágil e sujeita a forças maiores do que o sujeito (Rimbaud) ou a desaparição do poeta (Mallarmé) em prol das articulações próprias e inesperadas das palavras, em seu universo próprio, material e sonoro. Algo parecia estar mudando no estatuto do sentido.

Se levarmos para o campo do pensamento e das ciências humanas, veremos que, segundo Foucault, novas possibilidades de interpretação teriam sido radicalmente inauguradas na Modernidade pela tríade "Nietzsche, Freud, Marx". ${ }^{2}$ Nasceria aí o sistema de interpretação em que nos encontramos talvez até hoje, no século XXI, ao menos desde o que Foucault entende por episteme moderna. ${ }^{3}$ Trata-se, nos três casos, da abertura de importantes "feridas no pensamento ocidental", diz Foucault, de verdadeiras rupturas com a cultura até então vigente. Nietzsche, Freud, Marx seriam responsáveis pela irrupção de pressupostos que tantas vezes hoje, para nós, soam até mesmo indiscutíveis, pois foram de certo modo naturalizados entre nós como, por exemplo, a ideia de um sentido múltiplo contido em cada texto. 
Dentre os pressupostos trazidos por esses pensadores-chave de uma certa hermenêutica moderna, para Foucault, a ausência de fundamento talvez seja um dos primeiros e mais importantes. Com eles, em suas "técnicas interpretativas" é como se fossem abolidos definitivamente os pontos de partida e de chegada: não há mais origem, verdade ideal ou absoluta. Ou seja, ao contrário da hermenêutica clássica, já não se busca mais um fundamento, não há mais a crença em um ponto original a ser restituído. Hoje, por exemplo, é comum que qualquer análise proposta acerca de um texto literário coloque-se como algo parcial, ciente de ser uma das perspectivas dentre muitas, lançando mão de expressões como "longe de esgotar os sentidos possíveis" ou "sem querer pretender-se a única ou verdadeira leitura da obra" etc. Nessas afirmações, temse a contestação de toda uma tradição da hermenêutica teológica que teria em vista desvendar a palavra de Deus, colocando a exegese como essencialmente a busca por um sentido originário, verdadeiro, do qual a Sagrada Escritura seria a portadora. Podemos dizer que a presença desse sentido verdadeiro no entanto acaba sendo transferida para outros campos, como a figura do autor, por exemplo, no Romantismo. E mesmo quando a hermenêutica passa a ser aplicada a textos literários, ela guarda a concepção de um sentido absoluto, verdadeiro, a ser descoberto, interpretado, trazido à luz pelo bom intérprete.

A partir desses hermeneutas modernos, assim, para Foucault, o ponto chave inicial é que não há mais um sentido verdadeiro e único a ser desvendado, o que coloca em xeque um pressuposto definidor da tradição interpretativa tal como ela se consolidou entre nós. De modo que, para Foucault, a ruptura trazida por esses pensadores configura um rasgo real, uma trinca irreversível na geografia de nossa cultura. Isso não significa que outros sistemas de pensamento não continuem a existir a partir de então, que ocorra uma substituição a cada corte epistemológico; ao contrário, na ideia de tempo implicada em Foucault, devemos ter que essas diversas epistemes, que se sucedem a partir de interrupções, quebras, coexistirão sempre, em uma heterogeneidade temporal, como camadas de uma rocha que se sedimentam e que estão atuando conjuntamente a todo instante.

Daí uma das consequências importantes para nosso modo de ver a interpretação: com a extração da ideia de origem, a partir do momento em que não há ponto de partida ou chegada a ser alcançado ou recuperado, a interpretação transforma-se em uma tarefa sem começo nem fim, que pode ser desdobrada ao infinito. Na hermenêutica moderna, o intérprete tem a consciência de que não chegará até o fim de sua interpretação, pois já sabe de antemão que este fim encontra-se em uma espécie de ponto cego, ou de "zona perigosa", como o diz Foucault. Neste ponto, estaria em jogo o desaparecimento do próprio intérprete: em Freud, por exemplo, para quem a análise é interminável, infinitamente desdobrável, este ponto cego estaria no que ele chamou de transferência, ponto inatingível e sempre presente, em que a análise se volta para o próprio analista (o intérprete, portanto). No desdobramento infinito da interpretação há um momento em que ela irremediavelmente volta-se sobre si, retorna e se retoma, em um movimento circular. 
Ao caráter infinito da interpretação, ligam-se estes dois princípios ou postulados da hermenêutica moderna para Foucault, nos quais reconhecemos muito de nossas práticas de leitura literária hoje: 1) nada há a interpretar, posto que nunca se chega ao fim, ou à origem, de coisa alguma - logo, tudo é interpretação; 2) a interpretação se retoma infinitamente: é sempre interpretação de alguém e sempre deve se auto-interpretar, retornar a si mesma. Assiste-se a uma espécie de generalização do termo interpretação, no sentido de versão ou perspectiva. "Nada há a interpretar" porque "tudo já é interpretação": o intérprete moderno sabe que interpreta interpretações para chegar a novas interpretações. Pressupostos que, afinal, estamos acostumados a tomar de partida hoje em grande parte das críticas de arte ou literatura.

Assim, se tudo é interpretação, teremos como consequência que o signo deixa de ser um reservatório que guarda a verdade das coisas. Não se trata mais de interpretar o signo para se encontrar a verdade que estaria nele escondida, o signo não é mais um significante que carrega o sentido verdadeiro do estado de coisas ao qual se refere. A partir de Nietzsche, mas também de Freud e Marx, para Foucault, é como se deixássemos de acreditar nos signos, conscientes de que "o signo já é uma interpretação que não se dá como tal". ${ }^{4} \mathrm{O}$ signo traveste-se de uma pureza, de uma imediaticidade que nada mais é do que uma capa que esconde sua real natureza: a de se originar de uma construção, uma leitura, uma criação.

De modo que surge a consciência de que qualquer palavra já é, por sua vez, a construção de uma perspectiva, ou a apresentação de uma leitura dentre muitas, o que será a insistência de Nietzsche desde que era professor de filologia, ou seja, desde suas primeiras obras. Para Nietzsche, salienta Foucault: "As próprias palavras não passam de interpretações". ${ }^{5}$ Ao falar das figuras de linguagem, os tropos (como metáfora, metonímia, sinédoque, os que são por ele abordados nesta aula sobre a retórica), afirma Nietzsche, em Da retórica:

Entre os mais importantes artifícios da retórica contam-se os tropos, as designações impróprias. Mas todas as palavras são em si e desde o começo, quando à sua significação, tropos. ${ }^{6}$

Todas as palavras são, no fundo, designações impróprias: tanto aqui quanto em Sobre verdade e mentira no sentido extra-moral, Nietzsche nos lembra do caráter artificial e aleatório da própria origem da linguagem; não há naturalidade da linguagem, ela é artifício por definição, é construção desde sua origem mais remota. "O que é uma palavra? A figuração de um estímulo nervoso em sons". ${ }^{7}$ Trata-se de camadas e camadas de metáforas; se buscarmos a palavra ali, em seu instante de surgimento, encontraríamos: o estímulo que se transforma em imagem (primeira metáfora), a imagem que se transforma em som (segunda) e assim por diante, em uma cadeia de metáforas aleatórias. 
A partir de Nietzsche fomos impelidos a enxergar que tudo é máscara, disfarce. $O$ homem vive em um mundo de ilusões criado por seu intelecto, como armaduras de proteção contra a crueza, a instabilidade e a efemeridade da vida - assim a linguagem, o conhecimento, assim a moral, a religião, assim a beleza e a metafísica. São artifícios que o intelecto cria para manter o homem vivo, para seduzi-lo à existência. Nietzsche faz a equivalência, que para muitos poderia soar estranha, entre ciência ("verdade") e arte ("ilusão"); para ele, ambas equivalem do ponto de vista de sua função vital, pois são igualmente ilusões necessárias à vida. Ambas são criações humanas.

Logo, o conhecimento para Nietzsche não implica em desvendamento, mas em construção, criação. A "origem" (no sentido de começo) do conhecimento deve ser identificada na tentativa do homem de criar pontos fixos e seguros em meio ao maremoto da vida, propor o "ser" como armadura de proteção ao "devir" - tal a imagem do homem "dependurado sobre as costas de um tigre". ${ }^{8}$ Conhecer, interpretar: nenhuma das atividades humanas é separável da idéia de criação. Em contraposição à idéia de decifração do signo, desmascaramento, termos que interpretar é, invariavelmente, deslocar, multiplicar, desdobrar em novas conexões. Afinal, ao retirar uma máscara, a partir de Nietzsche, sabemos que não encontraremos o rosto da verdade, mas sempre outra e outra máscara, e prosseguiremos em um descascar infinito de camadas, em um desdobrar infinito de disfarces, simulacros.

A "arqueologia", enquanto metodologia filosófica criada por Foucault - talvez um dos mais importantes filósofos do século XX que encontram na revolução de Nietzsche a condição de seu pensamento -, encontra-se alinhada com essa imagem: método que consiste em mapear as camadas de discurso que se sedimentaram e formaram, por exemplo, o conceito de loucura através dos tempos. ${ }^{9}$ Que camadas há por trás disto que hoje nós nomeamos por loucura? Não se trata de recorrer à história para cavoucar o fenômeno da loucura e encontrar ali, em seu cerne, uma "loucura em si". Mas, sim, de escavar a construção do conceito, a partir dos discursos sobre a loucura, tal como se deram em diferentes épocas e culturas. Observar a montagem do conceito, como que de dentro para fora. Posteriormente, Foucault somará outros elementos ao discurso, passando a considerar todo o dispositivo - que implica basicamente em todas as relações de poder - em que o discurso está tomado. Aqui, na passagem de uma arqueologia para uma genealogia, importa para nós apenas essa constância da revolução nietzscheana acerca do conhecimento e da cultura.

Foucault observará que, no seu método filosófico, o ato de escavar ou descascar camadas não deve ser entendido como uma escavação ao cerne de um indivíduo, à sua essência, no sentido de uma interiorização, de um movimento centrípeto, como poderíamos pensar ao fazermos por exemplo uma analogia com o desfolhar de uma cebola. Mas se, desde Nietzsche, cabe ao intérprete escavar os subterrâneos, não seria senão para, segundo Foucault, "percorrer os signos para denunciá-los, descer até o fim da linha vertical e mostrar que essa profundidade da interioridade é, na verdade, outra 
coisa do que ela diz". ${ }^{10}$ A partir daí, surge o que é um ponto fulcral na leitura de Foucault sobre as possibilidades abertas por Nietzsche e, em seguida, por Maurice Blanchot: desdobrar da interpretação não significa mais a busca de um núcleo essencial escondido no "âmago das profundezas", mas um movimento inverso; trata-se de um desdobramento para o exterior, para o fora - o que tão belamente vemos exposto no ensaio em homenagem a Blanchot, "O pensamento do exterior". ${ }^{11}$

A interpretação tida no sentido que ela adquire a partir de Nietzsche, Freud, Marx, segundo Foucault, torna-se esta tarefa infinita, sem fundo, que se faz em um contínuo desenrolar para fora de si, para o futuro. Para Foucault, neste que ele denominou como o "pensamento do fora", ou do exterior, Maurice Blanchot seria sua grande voz. A reflexão acerca da literatura em Blanchot relaciona-se diretamente com todo este deslocamento da interpretação. Nesse movimento, mostra-se então, diz Foucault, que a tal profundidade, ou a "verdade", essas ilusões nada mais são do que dobras da superfície. Uma dobra em que o exterior é momentaneamente tomado como interior. Mais uma máscara, se quisermos.

Voltamos à dinâmica a que somos conduzidos na ideia de conhecimento enquanto criação para Nietzsche: o conhecimento é um desdobrar para fora, para o futuro, no sentido da invenção de conceitos, funções, e mesmo necessidades, é, portanto, a própria edificação da cultura. O movimento do desbravador em direção ao desconhecido, não para desvendá-lo mas para criá-lo, como abertura de campos novos, a inauguração de novos espaços de pensamento antes impensáveis. Temos aqui presente não mais a ideia de "um pensamento que se interioriza," para usar os termos de Foucault ${ }^{12}$, mas um pensamento que se volta para o exterior, que busca desenrolar-se para fora de si, criar conexões inéditas. Trazer ao mundo o que ainda não há.

A partir desta concepção, o interpretar, a busca por compreender, dar sentido, ganha certamente um outro caráter. Interpretar passa a ser invariavelmente criar, logo, criar novos sentidos. A interpretação deixa de ser a busca por uma verdade escondida nas coisas e expressa em uma proposição reveladora do sentido do mundo. Se de início, na exegese da Sagrada Escritura, interpretava-se para encontrar ou reconhecer a verdade divina, se em Schleiermacher o intérprete se esforça por descobrir a intenção, logo, a verdade do autor ${ }^{13}$ (mesmo que na compreensão já haja a idéia de reconstrução), a partir da hermenêutica moderna a interpretação se vê diante da tarefa de se autoquestionar: não há verdade a ser alcançada... para que deve nos servir, portanto, a interpretação? $\mathrm{E}$ como fazê-la? O interpretar ganha um outro estatuto, e mesmo uma outra função. 


\section{O sentido como efeito incorporal}

Sabe-se da aversão de Deleuze e Guattari à ideia de interpretação, o que vez por outra é retomado por eles, em diferentes momentos de suas obras, a começar por Kafka por uma literatura menor em que afirmam, logo na primeira página, que nada há a interpretar na obra de Kafka, e opõem à interpretação o conceito de experimentação. Ou em O antiÉdipo, ao opor a leitura a uma busca por significados e por desvendamento de significantes e, ainda, em Mil platôs, em inúmeras passagens em que defendem não somente a experimentação mas a ideia de produção e de criação de mapas, ao exporem sua ideia de leitura. Isso apenas para enumerar as obras de Deleuze escritas em parceria com Guattari, em que talvez a questão tenha sido colocada de modo mais explícito. Poderíamos encontrar nas suas outras obras diferentes modos de se opor à prática da interpretação, tal como foi comumente tratada na tradição ao menos, e seu conceito de sentido pode ser um dos mais radicais modos de desconstruir as bases mesmas de qualquer hermenêutica.

Entretanto, ao dedicar um artigo, "Theatrum philosophicum"14 (1970), a duas obras de Deleuze, Diferença e repetição (1968) e Lógica do sentido (1969), temos a impressão de que Foucault coloca a filosofia de Deleuze na esteira das rupturas de Nietzsche, Freud, Marx, em suas aberturas a novas possibilidades de exegese. O que chamará a atenção de Foucault será sobretudo o conceito deleuzeano de sentido, que teria como mérito desvincular o sentido das dimensões estritamente discursivas e, simultaneamente, desvinculá-lo do objeto e do sujeito. A importância e novidade trazida pelo conceito de Deleuze (e também por toda a sua filosofia da diferença, à qual o conceito se vincula) é tratada com entusiasmo por Foucault, por libertar o sentido dessas sujeições e trazer, por fim, uma possibilidade de enfim pensar-se o acontecimento. Fator central, para ele, em uma virada nas técnicas interpretativas na modernidade.

Se pensarmos que a empreitada de Foucault consiste em deformar, torcer e reinventar o conceito de interpretação, talvez possamos ligar a quebra trazida por Deleuze àquela que constitui uma nova "virada hermenêutica" em Foucault. Independentemente dos meandros terminológicos aí implicados (não é nosso objetivo discutir a pertinência ou não, hoje, dos termos hermenêutica e interpretação), o que nos interessa é destacar a ressonância dessas concepções, naquilo que concerne a novos modos de ler, analisar e apreender a literatura e as artes hoje. Certamente não foram tiradas ainda todas as consequências da revolução que um conceito de sentido como o de Deleuze traria para os estudos literários, por exemplo. Nem teríamos ainda a resposta, hoje, dos limites a que esse conceito empurra a própria noção de teoria ou análise literária. Daí por que ainda nos caiba destacar esse conceito, dentro de um contexto como aquele proposto por Foucault no qual, parece-nos, há a proposta de um novo conceito de interpretação. 
Deleuze traz em Lógica do sentido uma bonita descrição do sentido como uma "tênue película no limite das coisas e das palavras" ${ }^{15}$, um efeito que se produz na fronteira dos estados de coisas e das proposições, como resultado deste encontro. Efeito que, embora expresso nas proposições e sendo atributo dos estados, não se confunde com nenhum deles. O sentido é algo que "acontece", enquanto efeito produzido no encontro das palavras com os corpos. Há portanto algo de inapreensível na natureza do sentido. Em vários momentos do livro, Deleuze vai reiterar que "não podemos nem mesmo dizer, a respeito do sentido, que ele exista". ${ }^{16}$ O sentido "não existe", mas apenas "insiste" na proposição que o exprime. Chega-se a ler, no prólogo de Lógica do sentido, que o sentido é uma "entidade não-existente". De modo que a proposta de Deleuze de um sentido como um acontecimento incorporal, que afeta os corpos, daria testemunho de um pensamento de uma "materialidade incorpórea", diz Foucault, arriscando que esse termo talvez não fosse do agrado de Deleuze. ${ }^{17} \mathrm{O}$ que se joga aí, diz, é uma filosofia do fantasma, uma reversão completa da metafísica, em que o sentido ganha essa natureza de acontecimento.

Pensar o sentido enquanto "acontecimento", efeito incorporal dando-se nos corpos, implica que ele extrapola o estado de coisas em que se atualiza, bem como a designação das coisas na linguagem. É o verbo no infinitivo, como o exemplo do "morrer", dado por Foucault: "[A frase] 'Marco Antonio está morto' designa um estado de coisas; expressa uma opinião ou uma crença que eu tenho; significa uma afirmação; e, aliás, tem um sentido: o 'morrer'”. ${ }^{18} \mathrm{O}$ morrer seria o acontecimento limite, acontecimento por excelência: morrer exprime um estado de coisas, é expresso em uma proposição ("fulano morreu") mas o sentido mesmo é o morrer, esse movimento que o verbo tenta captar: efeito incorporal que se dá no corpo, que o afeta, que é expresso na linguagem pelo verbo no infinitivo. Quando digo "fulano morreu", o sentido não está nem na minha frase, nem no corpo morto, mas o sentido é esta ação, que aconteceu ao corpo, que o afetou, efeito incorporal que se deu no corpo e que agora exprimo em minha proposição.

Não entraremos por hora em mais detalhes acerca do complexo conceito de sentido operado por Deleuze ${ }^{19}$; dele, queremos apenas nos deter neste fato: a emergência do sentido como fabricação, criação, que se dá enquanto efeito produzido na superfície dos corpos. Deve-se levar em conta, ao mesmo tempo, que não se trata de uma criação aleatória, a ser confundida com um "vale tudo", mas sim que o sentido como um "efeito produzido" implica a ideia de uma criação que está longe de ser a criação "de" um sujeito ou uma consciência. Trata-se de um efeito provocado no encontro, no choque entre $\operatorname{corpos}^{20}$ e para além de qualquer escolha ou voluntarismo. Daí que o sentido não é mais algo preexistente, alojado nos estados de coisas e simplesmente representado na linguagem - mesmo que compreendamos que a linguagem não é capaz de captar o fenômeno em sua totalidade, que a palavra é insuficiente para abarcar a experiência, etc. Não há uma incapacidade da linguagem em representar o sentido, tampouco artimanhas das palavras em escondê-lo - como muitas leituras críticas de literatura, principalmente quando tratam do poema, já usaram acreditar. O sentido é um limiar, uma encruzilhada, 
é a linha-limite, borrada, entre corpos e palavras, dando-se em um movimento de mão dupla intermitente, entre a linguagem e as coisas.

Deleuze insistirá em diversos outros momentos de sua obra nessa premissa de um sentido enquanto efeito, maquinação, fabricação, contestando a noção corrente de um sentido (bem como de uma memória ou um inconsciente) enquanto reservatório de conteúdos. Em um de seus ensaios compilados em Ilha deserta, por exemplo, Nietzsche e Freud ${ }^{21}$ aparecem como seus aliados nessa nova concepção de sentido, com o que reencontramos ecos da leitura foucaultiana:

Em Nietzsche, em Freud [...] a noção de sentido é instrumento de uma contestação absoluta, de uma crítica absoluta, e também de uma criação determinada: o sentido não é de modo algum um reservatório, nem um princípio ou uma origem, nem mesmo um fim: é um 'efeito', um efeito produzido, do qual é preciso descobrir as leis de produção. ${ }^{22}$

A filosofia de Deleuze também deve ser localizada na esteira disso que ele nomeia por uma "contestação absoluta" e "crítica absoluta", a partir das quais se faz necessária toda uma transformação na ideia de interpretação ou análise, e implicará em uma quebra epistemológica nos estudos literários, como nos artísticos de modo mais geral - tal o empreendimento proposto acerca da esquizoanálise, por exemplo, com Guattari, em 0 anti-Édipo (1972). Tanto em uma análise literária quanto em uma psicanálise, o advento de uma revolução no conceito tradicional de sentido implicará sobretudo em novos métodos, em novas práticas, como veremos em seguida proposto e realizado em Mil platôs, sobretudo, na imagem do rizoma.

Será toda a ideia de leitura que sofrerá um abalo, a partir do momento em que já não se crê em um sentido original, contido na obra ou no autor, e a partir do momento em que o sentido é sempre algo novo, produzido a cada vez, enquanto efeito de embates que se renovam a cada leitura - entre texto, leitor, ambientes, épocas, etc. E, ainda, a partir do momento em que o sentido é anterior ao sujeito, foge portanto de sua "boa vontade" em criá-lo; somos a todo tempo tomados por sentidos que nos afetam, corporalmente, com a violência de tudo o que é novo e desconhecido: o sentido será, por definição, não-senso, para Deleuze. Será sempre de natureza paradoxal, o sentido se fabrica aí, por força de um encontro que abre um ponto em branco, um não-senso, como vácuo de origem.

"Mas a única questão, quando se escreve, é saber com que outra máquina a máquina literária pode estar ligada, e deve ser ligada para funcionar", lemos no platô "Rizoma". ${ }^{23}$ É preciso um vazio para que o sentido se crie, enquanto novo. Um novo uso, novos acoplamentos. O que pressuporá um uso produtivo e experimental da literatura. Ideia presente desde $O$ anti-Édipo, em que o sentido já aparece ligado ao uso produtivo da literatura: "a mais alta potência da linguagem foi descoberta quando se considerou a obra como uma máquina produzindo certos efeitos, capaz de um certo uso". ${ }^{24}$ Um uso produtivo do texto, único modo de o colocar em movimento: 
Porque ler um texto não é nunca um exercício erudito em busca dos significados, menos ainda um exercício altamente textual em busca de um significante, mas um uso produtivo da máquina literária, uma montagem de máquinas desejantes, exercício esquizóide que retira do texto sua potência revolucionária. ${ }^{25}$

O uso produtivo ou a experimentação é, ainda, o que Deleuze chamará de uma leitura em intensidade, aquela que faz passar algo, que não é da ordem da significação, apenas, ou da compreensão. Ler literariamente seria, a partir dessa perspectiva, algo distante do entendimento, como para Blanchot: "Ler, no sentido da leitura literária, não é sequer um movimento puro de compreensão, o entendimento que manteria o sentido perseguindo-o com insistência. Ler situa-se aquém ou além da compreensão". ${ }^{26}$ Ler tampouco é descobrir a obra única que estaria por detrás, diz Blanchot. Esse outro modo de ler, para Deleuze, é o que considera o livro como uma maquinaria sem significado prévio, com a qual posso me acoplar e criar novos sentidos, novos percursos.

Por hora, fiquemos com essas imagens que indicam possíveis saídas para a leitura literária, pensada mais proximamente a um ato de experimentação do que propriamente de compreensão ou entendimento. Talvez o interpretar aqui, se seguirmos a ideia de Foucault, possa ser uma espécie de contra-interpretação (no viés tradicional), aproximando-se mais à interpretação de um instrumentista, por exemplo, que a partir de sua técnica interpretativa não procura traduzir uma partitura mas sim repeti-la diferencialmente a cada performance. Seguir seu fluxo e criar um novo percurso, um novo mapeamento de gestos, sonoridades, ritmos.

Vale transcrever o trecho todo em que Deleuze situa dois modos diversos de leitura e relação com o texto e em que afirmará afinal: "Não há nada a explicar, nada a compreender, nada a interpretar. É do tipo ligação elétrica":

É que há duas maneiras de ler um livro. Podemos considerá-lo como uma caixa que remete a um dentro, e então vamos buscar seu significado, e aí, se formos ainda mais perversos ou corrompidos, partimos em busca do significante. E trataremos o livro seguinte como uma caixa contida na precedente, ou contendo-a por sua vez. $\mathrm{E}$ comentaremos, interpretaremos, pediremos explicações, escreveremos o livro do livro, ao infinito. Ou a outra maneira: consideramos um livro como uma pequena máquina asignificante; o único problema é: 'isso funciona, e como é que funciona?' Como isso funciona para você? Se não funciona, se nada passa, pegue outro livro. Essa outra leitura é uma leitura em intensidade: algo passa ou não passa. Não há nada a explicar, nada a compreender, nada a interpretar. É do tipo ligação elétrica. ${ }^{27}$

\section{bibliografia complementar}

DELEUZE, G.; GUATTARI, F. Kafka, pour une littérature mineur. Paris: Minuit, 1975.

FOUCAULT, M. A ordem do discurso. Tradução de Laura Fraga de Almeida Sampaio. São Paulo: Edições Loyola, 1996 (Original: L’Ordre du discours, 1971). 
* Annita Costa Malufe é professora de filosofia da PUC/SP.

${ }^{1}$ FOUCAULT, M. "Nietzsche, Freud, Marx". In: Ditos e Escritos II. Tradução de Elisa Monteiro. Rio de Janeiro: Forense Universitária, 2000, p. 41 (Original: Dits et Écrits, 1994).

${ }^{2}$ FOUCAULT, M. "Nietzsche, Freud, Marx". Op. cit., pp. 40-55.

${ }^{3}$ Tenho em vista aqui o conceito de "episteme", trabalhado por Michel Foucault em As palavras e as coisas, segundo o qual a episteme moderna, a que teria como marco o pensamento de Kant (o homem histórico, a morte de Deus), encontraria seus limites com Nietzsche e com certas ideias de literatura que permeiam o século XX e nos mostram a formação de uma nova episteme. Foucault, porém, não chega a nomear mas apenas indicar - ali, em 1966, quando escreve o livro, já sentia se delinear uma ruptura epistemológica, uma nova descontinuidade na história da cultura ocidental (ruptura com a cultura humanista) mas à qual ele alude sem desenvolver (Cf. Idem. Les Mots et les choses. Paris: Gallimard, 1966, especialmente cap. X).

${ }^{4}$ FOUCAULT, M. "Nietzsche, Freud, Marx". Op. cit., p. 48.

${ }^{5}$ Ibidem.

${ }^{6}$ NIETZSCHE, F. Da Retórica. Tradução de Tito Cardoso e Cunha. Lisboa: Passagens, 1999, p. 46.

${ }^{7}$ Idem. Sobre verdade e mentira no sentido extra-moral. Tradução de Fernando de Moraes Barros. São Paulo: Hedra, 2007, p. 30.

${ }^{8}$ Ibidem, p. 29.

${ }^{9}$ Aqui especificamente referimo-nos ao célebre estudo de Foucault, História da loucura [Histoire de la folie à l'âge classique].

${ }^{10}$ FOUCAULT, M. "Nietzsche, Freud, Marx". Op. cit., p. 44.

${ }^{11}$ Idem. "O pensamento do exterior". In: Ditos e Escritos III. Tradução de Inês Autran Dourado Barbosa. Rio de Janeiro: Forense Universitária, 2001 (Original: Dits et Écrits, 1994).

12 Ibidem, p. 226.

${ }^{13}$ Schleiermacher diz que "a mais alta completude da interpretação consistiria em compreender um autor melhor do que ele de si mesmo pode dar conta [...]" (Hermenêutica, arte e técnica da interpretação. Tradução de Celso Reni Braida. Bragança Paulista: Editora Universitária São Francisco, 2003, p. 43).

${ }^{14}$ FOUCAULT, M. "Theatrum philosophicum". In: Ditos e Escritos II. Tradução de Elisa Monteiro. Rio de Janeiro: Forense Universitária, 2000 (Original: Dits et Écrits, 1994).

15 DELEUZE, G. Lógica do sentido. Tradução de Luiz Roberto Salinas Fortes. São Paulo: Perspectiva, 1974, p. 34 (Original: Logique du sens, 1969).

16 Ibidem, p. 21.

${ }^{17}$ FOUCAULT, M. “Theatrum philosophicum”. Op. cit., p. 233.

${ }^{18}$ Foucault continua: "Sentido impalpável do qual uma face está virada para as coisas, posto que 'morrer' sucede como acontecimento a Antonio, e a outra está virada para a proposição, posto que morrer é o que se diz de Antonio num enunciado”. Ibidem, p. 236.

${ }^{19}$ Trabalhei mais diretamente acerca do conceito de Deleuze no artigo: "Deslocamentos do sentido em Deleuze: implicações para a leitura". In: Revista Alegrar, n. 8 (dezembro de 2011). Disponível em <http://www.alegrar.com.br/revista08/pdf/deslocamentos_malufe_alegrar8.pdf>. Acesso em 05.09.2016. 
${ }^{20}$ Referimo-nos à concepção de "corpo" tal como se dá em Deleuze a partir de Espinosa - um conceito mais amplo, que se refere a qualquer agente, a qualquer "ser" portador de potência de agir: neste sentido, um texto é um corpo, a linguagem é um corpo, etc.

${ }^{21}$ Ainda que em outros contextos - especialmente em $O$ anti-Édipo - Freud apareça justamente como o representante de um conceito de inconsciente enquanto reservatório e teatro.

22 "Chez Nietzsche, chez Freud, c'est le contraire: la notion de sens est l'instrument d'une contestation absolue, d'une critique absolue, et aussi d'une création déterminée: le sens n'est pas du tout un reservoir, ni un principe ou une origine, ni même un fin: c'est un 'effet', un effet produit, et dont il faut découvrir les lois de production". DELEUZE, G. "Sur Nietzsche et l'image de la pensée". In: L'île déserte et autres textes, Paris: Minuit, 2002, p. 189. "Em Nietzsche, em Freud, é o contrário: a noção de sentido é o instrumento de uma contestação absoluta, de uma crítica absoluta, e também de uma criação determinada: o sentido não é, de modo algum, um reservatório, nem um princípio ou uma origem, nem mesmo um fim: é um "efeito", um efeito produzido, cujas leis de produção devem ser descobertas". DELEUZE, G. A ilha deserta e outros textos. "Sobre Nietzsche e a imagem do pensamento". São Paulo: Iluminuras, 2006, p. 177.

${ }^{23}$ DELEUZE, G; GUATTARI, F. Mil Platôs, vol. 1. Tradução de Aurélio Guerra Neto e Celia Pinto Costa. São Paulo: Editora 34, 1995, p. 12 (Original: Mille Plateaux, 1980).

${ }^{24}$ Idem. O anti-Édipo. Tradução de Luis B. L. Orlandi. São Paulo: Editora 34, 2010, p. 143 (Original: L'anti-CEdipe, 1972).

${ }^{25}$ Ibidem, p. 139.

${ }^{26}$ BLANCHOT, M. O espaço literário. Tradução de Álvaro Cabral. Rio de Janeiro: Rocco, 1987, p. 196 (Original: L'espace littéraire, 1955)

${ }^{27}$ DELEUZE, G. Conversações. Tradução de Peter Pal Pelbart. São Paulo: Editora 34, 2000, pp.16-17 (Original: Pourparlers 1972-1990, 1990). var gaJsHost = (("https:" == document.location.protocol) ? "https://ssl." : "http://www.");

document.write(unescape("\%3Cscript src="' + gaJsHost $\quad+\quad$ "google-analytics.com/ga.js' type='text/javascript'\%3E\%3C/script\%3E"));try \{

var pageTracker = _gat._getTracker("UA-8104146-2");

pageTracker._trackPageview();

\} catch(err) \{\} 